Disponível em

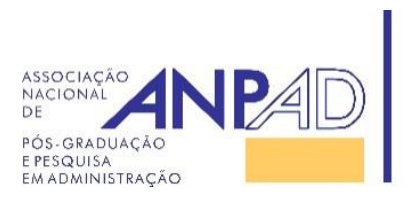

http://www.anpad.org.br/rac

RAC, Rio de Janeiro, v. 21, n. 4, art. 1, pp. 435-457, Julho/Agosto, 2017 http://dx.doi.org/10.1590/1982-7849rac2017160097

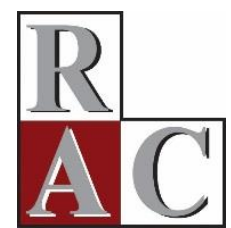

\title{
Intervenientes do Processo de Transferência Tecnológica em uma Universidade Pública
}

\author{
Intervenors in the Technology Transfer Process in a Public University
}

Rodrigo Assunção Rosa ${ }^{1}$ José Roberto Frega ${ }^{2}$

Fundação Getulio Vargas ${ }^{1}$ Universidade Federal do Paraná ${ }^{2}$

Artigo recebido em 05.05.2016. Última versão recebida em 28.12.2016. Aprovado em 29.12.2016. Publicado online em 11.04.2017. 


\title{
Resumo
}

Este estudo tem por objetivo investigar os intervenientes do processo de transferência tecnológica em uma universidade pública, analisando sua agência de inovação sob o ponto de vista da proteção de propriedade intelectual. A estratégia de Estudo de Caso único foi adotada por meio de entrevistas semiestruturadas com gestores da agência e com 13 pesquisadores que participam ativamente do processo, com coleta de documentos e observação direta. Como resultado, verificou-se que a institucionalização da agência foi precedida de uma série de estímulos governamentais de apoio à inovação e de parcerias realizadas com outras instituições. Identificaramse seus intervenientes, entre os quais as principais barreiras estão: sobrecarga de atividades, desconhecimento e desinteresse dos pesquisadores, deficiências no processo de redação da patente e carência de capital humano nas atividades da agência, burocracia e falta de suporte pela universidade. Já entre os facilitadores, estão: a experiência acadêmica por parte dos pesquisadores, a divulgação da cultura de propriedade intelectual, a terceirização do processo de redação da patente por parte da agência e de sua institucionalização pela universidade. Os pesquisadores são motivados a engajarem-se no processo de transferência tecnológica principalmente pela consciência sobre a relevância de proteger as descobertas, pelo acesso a recursos para pesquisa, pelos ganhos econômicos e pelo prestígio acadêmico.

Palavras-chave: cooperação universidade-empresa; transferência tecnológica; Escritório de Transferência Tecnológica; agência de inovação.

\begin{abstract}
The purpose of this study is to investigate intervenors in the technology transfer process in a public university, analyzing its innovation agency from the point of view of protection of intellectual property. A single case study strategy was chosen using semi-structured interviews with agency managers and 13 researchers who actively participate in the process, document collection and direct observation. Results show the institutionalization of the agency by the university was preceded by a series of government incentives to support innovation and by partnerships established with other institutions. The main barriers identified among the intervenors are: activity overload, a lack of knowledge and interest from researchers, deficiencies in the patent drafting process and lack of human capital in agency activities, bureaucracy and a lack of support by the university. Facilitators included researcher academic experience, dissemination of intellectual property culture, outsourcing of the patent drafting process by the agency and its institutionalization by the university. Researchers are encouraged to engage in the process of technology transfer particularly by awareness of the importance of protecting discoveries, access to research resources, economic gains, and academic prestige.
\end{abstract}

Key words: university-company cooperation; technology transfer; Technology Transfer Office; innovation agency. 


\section{Introdução}

Desde o final de 1970, uma terceira missão além do ensino e pesquisa é atribuída às universidades: a transferência de seu conhecimento para a sociedade (Etzkowitz, 2003; Kalar \& Antoncic, 2015). Por meio do processo de transferência tecnológica, as universidades têm colaborado de forma significativa para a atividade de inovação em diversos setores da sociedade, apresentando papel expressivo no desenvolvimento regional e nacional de diversos países (Muscio, 2010; Wu, Welch, \& Huang, 2015).

Nas últimas décadas, o governo brasileiro desenvolveu uma série de esforços na constituição de um ambiente favorável de incentivo à inovação, o que permitiu avanços consideráveis nesse cenário (Cruz, 2010). Uma das medidas adotadas, a Lei de Inovação (Lei n. 10.973, 2004), possibilitou a aproximação entre universidades, institutos de pesquisas e empresas por meio da regulamentação de atividades das Instituições Científicas e Tecnológicas (ICTs) e, a partir da disposição de Núcleos de Inovação Tecnológica (NITs) para a gestão de suas políticas de inovação, visando, assim, estimular o desenvolvimento industrial do país e a geração de inovações tecnológicas (Kruglianskas \& MatiasPereira, 2005; Lei n. 10.973, 2004).

A criação da Lei da Inovação e as ações desenvolvidas pelo Ministério da Ciência, Tecnologia e Inovação, pelas ICTs brasileiras e por outros agentes, possibilitaram que os NITs se institucionalizassem. Tal fato promoveu novos caminhos para que os resultados das pesquisas desenvolvidas nas ICTs se tornassem novos processos e produtos de aplicação industrial e comercial (Martins, 2010). Os Escritórios de Transferência Tecnológica (no caso do Brasil, os NITs ou Agências de Inovação) têm se consolidado mundialmente enquanto agentes intermediários da relação entre universidades e sociedade, sendo uma de suas finalidades a gestão e a proteção das patentes desenvolvidas pelos pesquisadores e a transferência dessas tecnologias às empresas (Fitzgerald \& Cunningham, 2016; Muscio, 2010).

Apesar de tais avanços, o Brasil ainda enfrenta obstáculos tanto externos, em suas políticas e sistema de inovação, quanto internos, em relação à gestão de transferência tecnológica das ICTs. Essas dificuldades evidenciadas por Livesey (2014) que, a partir de estudo com 33 NITs de diversas regiões do Brasil, permite constatar que quase metade dos núcleos pesquisados (54\%) não acredita receber o apoio governamental e o financiamento adequado para o desenvolvimento de suas atividades e cerca de $2 / 3$ dos respondentes $(63 \%)$ consideram que a transferência tecnológica não é parte da estratégia universitária. Além disso, diversas barreiras ainda podem ser encontradas, tais como: a estrutura reduzida dos ETTs, a falta de comunicação com o mercado, e a pouca experiência dos pesquisadores e ETTs em realizar a transferência tecnológica (Desidério \& Zilber, 2014).

Para o avanço dessas questões, pesquisadores propõem trabalhos que compreendam os efeitos da criação dos NITs em relação aos seus stakeholders (Dias \& Porto, 2013) e pesquisas que investiguem como podem ser consolidadas as interações entre os NITs e o mercado (Desidério \& Zilber, 2014). Além disso, torna-se importante que sejam efetuados estudos que verifiquem as barreiras que dificultam o processo de transferência tecnológica entre universidades e empresas (Eberhart \& Pascuci, 2014). Nesse sentido, este estudo tem o objetivo de investigar os intervenientes (barreiras, facilitadores e motivadores) do processo de transferência tecnológica em uma universidade pública, analisando sua agência de inovação sob o ponto de vista da proteção da propriedade intelectual.

\section{Os Escritórios de Transferência Tecnológica}

A transferência tecnológica entre universidades e empresas tem sido um fator impulsionador de inovações tecnológicas e também da competitividade das próprias empresas em diversos países (Bozeman, Rimes, \& Youtie, 2015; Siegel, Waldman, \& Link, 2003). A consolidação dos Escritórios de Transferência Tecnológica (ETTs) tornou-se realidade no mundo ao longo das últimas décadas, 
principalmente após a aprovação da lei de inovação dos Estados Unidos, conhecida como Lei BayhDole Act, instituída na década de 1980 (Hayter \& Rooksby, 2016; Kruglianskas \& Matias-Pereira, 2005).

Os ETTs têm auxiliado na difusão de inovações, reduzindo as barreiras entre universidades e empresas por meio de mecanismos que estimulam a transferência tecnológica (Muscio, 2010; Siegel et al., 2003). Muito dos ETTs estão incorporados à estrutura das universidades e têm se tornado estratégicos, seja na proteção das criações desenvolvidas por pesquisadores, seja na transferência e na comercialização do conhecimento acadêmico (O'Kane, Mangematin, Geoghehan, \& Fitzgerald, 2015).

Desse modo, os ETTs, enquanto intermediários do processo de transferência, têm auxiliado os pesquisadores na compreensão da relevância de proteger as descobertas científicas, dando suporte necessário tanto ao acesso a recursos essenciais em suas pesquisas quanto na divulgação das patentes resultantes das pesquisas no âmbito das universidades (Siegel et al., 2003).

Os pesquisadores muitas vezes desconhecem o potencial de aplicabilidade de suas descobertas, bem como os mecanismos de transferência tecnológica existentes na universidade para que a proteção de suas criações e para que a difusão de tecnologia com as empresas se efetive (Desidério \& Zilber, 2014; Santana \& Porto, 2009).

Desse modo, os ETTs têm se tornado guardiões da propriedade intelectual desenvolvida nas universidades, tornando-se divulgadores tanto das necessidades das empresas aos pesquisadores quanto das necessidades dos pesquisadores às empresas (Fitzgerald \& Cunningham, 2016; G. C. Ferreira, Sória, \& Closs, 2012; Siegel, Veugelers, \& Wright, 2007).

\section{Intervenientes do processo de transferência tecnológica}

O desempenho referente à transferência tecnológica entre universidades e empresas está relacionado a uma série de fatores institucionais, organizacionais e individuais (Siegel et al., 2003), incluindo também diferentes stakeholders (Vinig \& Lips, 2015). Tais elementos podem ser definidos enquanto intervenientes, ou seja, barreiras, facilitadores e motivadores que afetam o processo de transferência tecnológica na relação entre universidades e empresas (Noveli \& Segatto, 2012).

Brescia, Colombo e Landoni (2016) afirmam que os ETTs geralmente orientam-se por três principais atividades: a proteção da propriedade intelectual, a transferência de tecnologia (licenciamento) e o suporte as atividades de spin-off (incubação de empresas). O recorte teórico do presente estudo refere-se principalmente à atividade de proteção da propriedade intelectual. Contudo, cabe ressaltar que os intervenientes identificados na literatura também podem afetar as outras atividades do ETT.

$\mathrm{Na}$ seção seguinte, serão desenvolvidos os principais achados identificados a respeito dos intervenientes (barreiras, facilitadores e motivadores) relacionados ao ETT e aos pesquisadores.

\section{Barreiras e facilitadores do processo de transferência tecnológica nos Escritórios de Transferência Tecnológica}

As barreiras podem ser compreendidas como fatores que dificultam o processo de colaboração entre universidade e empresas, enquanto os facilitadores são aqueles que agilizam ou impulsionam esse processo (Noveli \& Segatto, 2012).

A estrutura dos ETTs é um dos elementos a ser levado em conta no gerenciamento da transferência tecnológica, sendo uma das variáveis que afetam seu desempenho (Rothaermel, Agung, \& Jiang, 2007). A estrutura reduzida do ETT e seu tempo recente de criação são fatores criadores de obstáculos no processo de transferência tecnológica. Já o capital humano nos ETTs está diretamente relacionado à capacidade de criação e de transferência tecnológica. 
Nesse sentido, o número reduzido de pessoas que trabalham nos ETTs, a rotatividade e a experiência pouco considerável em TT também são fatores criadores de barreiras em relação à transferência tecnológica (Desidério \& Zilber, 2014; Silva, Kovaleski, \& Gaia, 2013). Dentre o fator facilitador, Kaymaz e Eryiğit (2011) afirmam sobre a autonomia do ETT, pois desvinculam-no dos aspectos burocráticos relacionados à universidade, reduzindo o tempo referente à transferência tecnológica, e também facilitando o fluxo de informação e alinhamento de incentivos (Huyghe, Knockaert, Piva, \& Wright, 2016).

O aspecto comunicativo do ETT é também um elemento relevante. Cabe ressaltar, nesse contexto, que a divulgação das descobertas é uma das variáveis que tem permeado as pesquisas relacionadas aos ETTs (Rothaermel et al., 2007). Nesse sentido, podem-se identificar duas principais barreiras referentes ao ETT no processo considerado. Desidério e Zilber (2014) e Garnica e Torkomian (2009) afirmam que há falta de uma ampla divulgação da propriedade intelectual da universidade gerida pelos ETTs. Isso ocorre tanto em relação à divulgação das atividades dos ETTs para os pesquisadores quanto em relação à identificação e à prospecção de potenciais parceiros empresariais para a realização de licenciamento de patentes ou P\&D conjunto.

Desidério e Zilber (2014) salientam também que a falta de interação entre os departamentos de pesquisa da universidade e o ETT é um elemento que dificulta a interação e a transferência. Isso se dá devido à falta de canais e de caminhos que estreitem o relacionamento entre o ETT e os pesquisadores. Corroborando com esses aspectos, G. C. Ferreira, Soria e Closs (2012), a partir de um estudo de caso realizado em uma universidade privada, identificaram que a criação de mecanismos de divulgação para a disseminação da cultura de propriedade intelectual possibilitou o aumento das produções tecnológicas.

Dentre os fatores relacionados aos Custos de Transação do ETT foi identificado um maior número de barreiras: a dificuldade no processo de patenteamento e negociação; a complexidade de valoração da tecnologia; o conflito de interesses entre universidade e empresa no estabelecimento dos contratos; o sigilo do processo de patenteamento; os elevados tempo e custo para o registro e a manutenção das patentes acadêmicas. Desidério e Zilber (2014) e Garnica e Torkomian (2009) enfatizam a morosidade dos aspectos jurídico-administrativos, principalmente no processo de negociação.

Vale ressaltar que essa questão ainda é reforçada pela desinformação de ambas as partes (pesquisadores e gestores de empresas) durante o trâmite no processo de licenciamento. Garnica e Torkomian (2009) também identificam a ausência de financiamento para as estratégias internacionais de patenteamento como fator limitador da transferência tecnológica.

Finalmente, estudos como os de Lucena e Sproesser (2015) e Dias e Porto (2013) constatam que, em ETTs mais avançados, a redação das patentes geralmente é realizada por equipe especializada do ETT ou é terceirizada para um escritório especializado na redação de patentes, aspectos esses que facilitaram o processo de transferência tecnológica.

\section{Motivadores, barreiras e facilitadores do processo de transferência tecnológica sob a ótica do pesquisador}

Além dos aspectos relacionados ao ETT já mencionados na seção anterior, Wu, Welch e Huang (2015) identificaram que o patenteamento e o licenciamento são determinados também por fatores individuais dos pesquisadores. Assim como outras variáveis, a transferência tecnológica também pode ser explicada pelo interesse do pesquisador no engajamento de atividades que envolvam a comercialização das descobertas.

Desse modo, os intervenientes podem estar divididos em motivadores, barreiras e facilitadores relacionados aos aspectos individuais do principal agente dentro da universidade capacitado a realizar descobertas científicas a fim de posteriormente realizar a transferência tecnológica (Closs, Ferreira, Sampaio, \& Perin, 2012). Os motivadores estão relacionados aos motivos, interesses e estímulos que levam os atores envolvidos no processo de transferência a cooperar (Noveli \& Segatto, 2012). 
Para os pesquisadores, diversos são os motivos para a realização da transferência tecnológica. D’Este e Perkmann (2011) mostram os principais deles para que os pesquisadores se engajem na pesquisa acadêmica: (a) a exploração comercial da tecnologia ou do conhecimento; (b) a aprendizagem que o pesquisador obtém da experiência em cooperar com as empresas; (c) o acesso a financiamentos públicos; (d) acesso a recursos, tais como equipamentos, materiais fornecidos pelas empresas para a realização da pesquisa científica. Derrick (2015) afirma que, embora haja a possibilidade de ganhos econômicos para financiamento, os pesquisadores se envolvem com as atividades de transferência tecnológica mais como forma de promoverem suas carreiras pessoais.

Em relação às barreiras encontradas pelos pesquisadores, principalmente nos estudos brasileiros, pode-se mencionar que estão relacionadas à limitação que eles possuem na realização das atividades de transferência tecnológica. Nesse sentido, os estudos de Chais, Scopel, Machado e Oléa (2013), A. Ferreira, Amaral e Leopoldi (2013), Closs, Ferreira, Sampaio e Perin (2012) e Santana e Porto (2009) identificaram que as tarefas exigidas dos professores dentro das universidades nas atividades de docência, pesquisa e extensão acabam por sobrecarregá-los, não havendo tempo para a realização de atividades relacionadas à transferência tecnológica.

Muitos desses pesquisadores, conforme mencionado por Santana e Porto (2009), também são responsáveis por uma quarta atividade, a administrativa, devido ao fato de a universidade não dispor de equipes para suprir essas demandas. A falta de experiência prévia com as atividades de transferência tecnológica, a inexistência de recompensas adequadas em relação à transferência das descobertas, o desconhecimento dos mecanismos e a falta de capacidade de compreender a necessidade das empresas também são fatores que limitam o desempenho de muitos pesquisadores dentro da universidade (A. Ferreira, Amaral, \& Leopoldi, 2013; Garnica \& Torkomian, 2009).

Há também fatores individuais que vêm facilitando o engajamento dos pesquisadores, conforme constatado por Closs et al. (2012), como as experiências no exterior, a participação em eventos internacionais e a aproximação com empresas, além do relacionamento interpessoal entre professores, alunos e técnicos da universidade.

\section{Procedimentos Metodológicos}

Nesta pesquisa, adotou-se a estratégia de estudo de caso único integrado (Yin, 2015). Os estudos de caso investigam eventos recentes em que os limites entre fenômeno e contexto não estão nitidamente definidos, com o propósito de compreender e enfatizar o real contexto em que o fenômeno acontece (Eisenhardt \& Graebner, 2007; Yin, 2015).

A partir da revisão realizada na seção anterior, com base em pesquisas mais recentes sobre cooperação entre universidade e empresas em periódicos científicos nacionais e internacionais (A. Ferreira et al., 2013; Chais, Scopel, Machado, \& Oléa, 2013; Closs et al., 2012; Derrick, 2015; Desidério \& Zilber, 2014; D’Este \& Perkmann, 2011; Dias \& Porto, 2013, 2014; Garnica \& Torkomian, 2009; G. C. Ferreira et al., 2012; Huyghe et al., 2016; Kaymaz \& Eryiğit, 2011; Noveli \& Segatto, 2012; Santana \& Porto, 2009; Silva et al., 2013), foi possível desenvolver o modelo de análise por meio da identificação das dimensões relacionadas aos intervenientes (conforme Figura 1). 


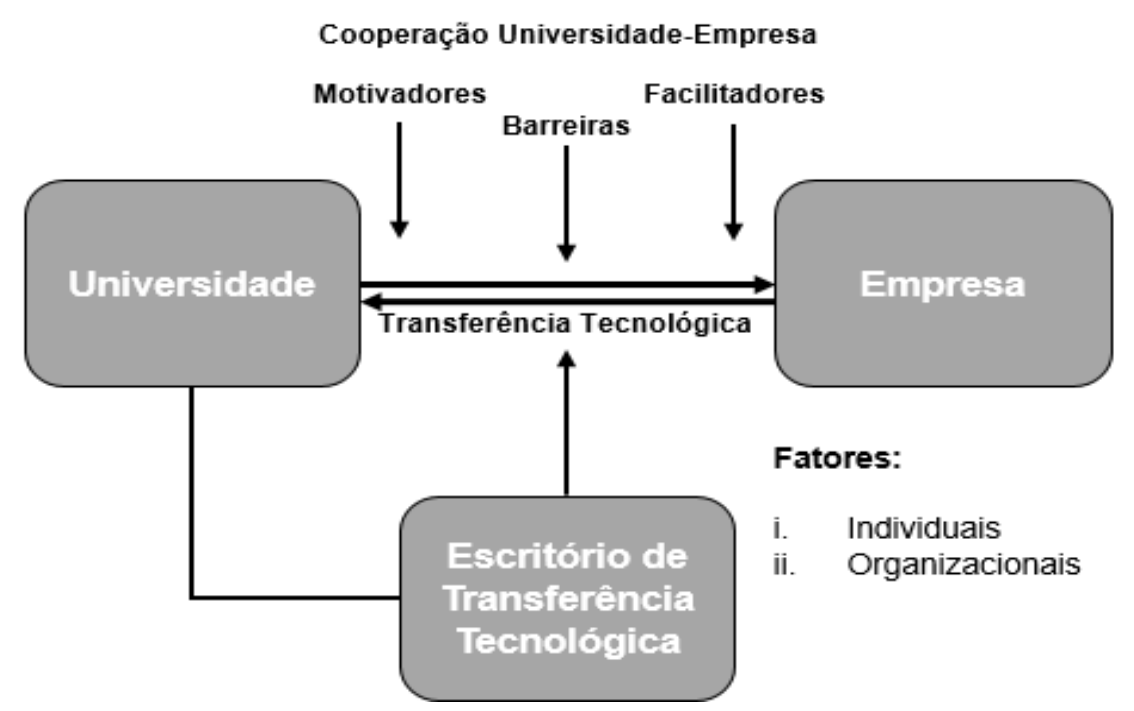

Figura 1. Fatores e Intervenientes do Processo de Transferência Tecnológica no Contexto da Cooperação Universidade-Empresa

O Escritório de Transferência Tecnológica analisado foi a Agência de Inovação da Universidade Federal do Paraná. A justificativa para sua escolha como caso único se deu devido ao fato de se tratar de um caso decisivo (Yin, 2015), que tem por finalidade confirmar ou rejeitar proposições de determinado conjunto de dimensões teóricas estabelecidas.

O caso de transferência tecnológica na Agência de Inovação da UFPR se torna interessante por três motivos: (a) De acordo com o Ranking Universitário Folha (2015) a UFPR é a quarta colocada na categoria inovação no país, atrás apenas da Universidade de São Paulo (USP), Universidade Estadual de Campinas (UNICAMP) e Universidade Federal de Minas Gerais (UFMG). Contudo, estudos recentes sob a ótica da gestão de transferência de tecnologia já foram realizados nesses principais NITs, entre os quais estão as pesquisas de Dias e Porto (2014) no caso da USP, Dias e Porto (2013) na UNICAMP, e Lucena e Sproesser (2015) no caso da UFMG; (b) De acordo com dados do Núcleo de Inovação Tecnológica do Paraná (NITPAR, n.d.), das treze ICTs do Estado do Paraná associadas ao NITPAR, a UFPR é a que possuí o maior número de patentes depositadas, representando 37,45\% do total de patentes depositadas entre os anos de 1998 e 2013 pelas ICTs, tendo um número três vezes superior de depósitos em relação à segunda universidade; (c) Um terceiro motivo deve-se ao fato que, a partir da análise dos depósitos de patentes realizados pelas ICTs do Paraná entre os anos de 1998 e 2013 de forma longitudinal, verificou-se que apenas na UFPR houve um crescimento considerável no número de depósitos de patentes, principalmente após a data de criação da Agência de Inovação da UFPR (Figura 2). Tais aspectos tornam interessante e oportuno o estudo de caso sobre o processo de transferência tecnológica nesse ETT. 


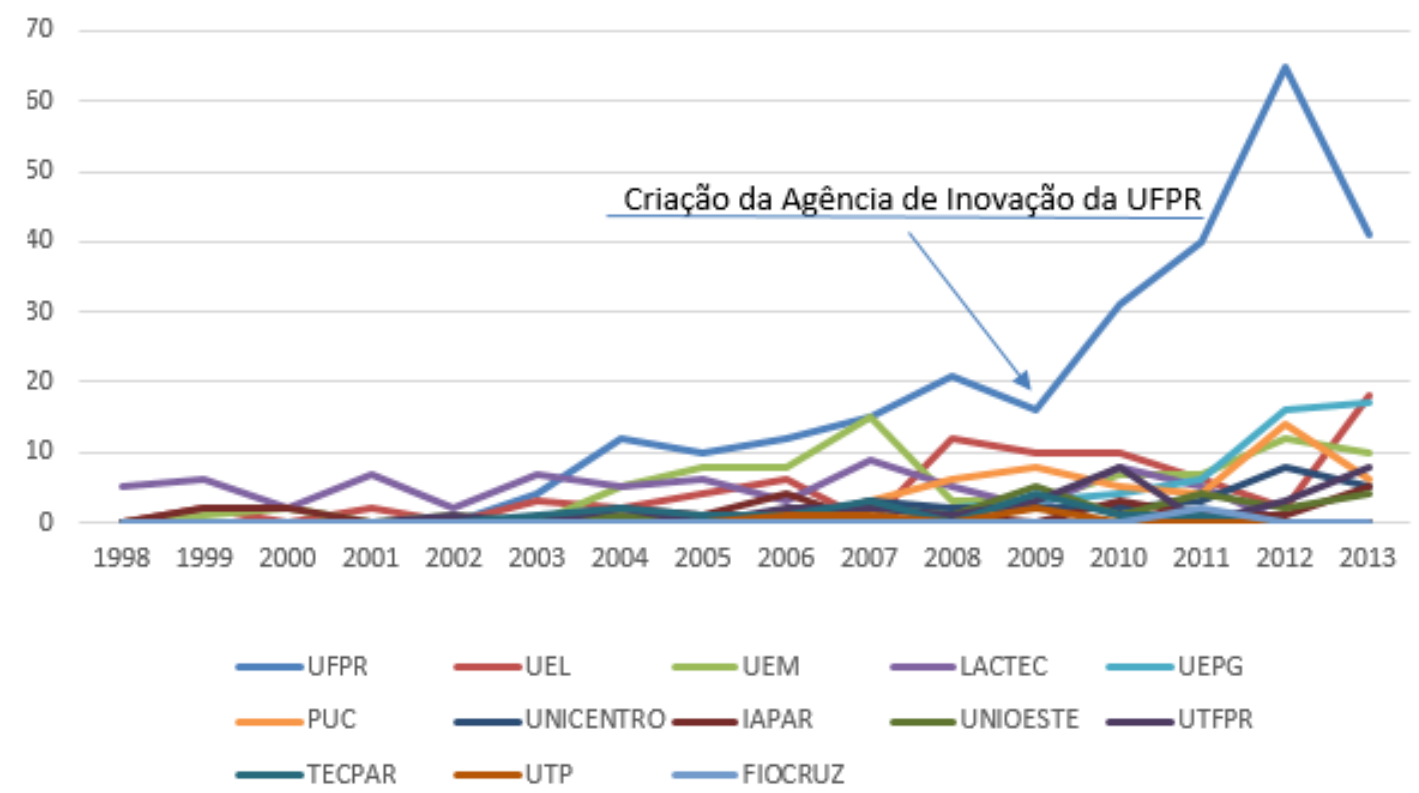

Figura 2. Quantidade de Depósitos de Patentes entre 1998 e 2013 do NITs do Paraná

$\mathrm{Na}$ coleta de dados, foram realizadas entrevistas semiestruturadas, coleta de documentos e observação direta. A escolha por esses três tipos de fontes de evidências foi feita devido ao fato de que a entrevista é uma das fontes mais relevantes de informação nos estudos de caso e a coleta de documentos e observação direta objetivam validar as evidências obtidas na entrevista, possibilitando a triangulação das fontes de dados (Yin, 2015).

As entrevistas semiestruturadas foram realizadas com pesquisadores (docentes) da Universidade Federal do Paraná, gestores da Agência de Inovação e outros sujeitos relevantes para a investigação (Tabela 1). O primeiro critério para a escolha dos docentes-pesquisadores participantes do estudo foi o número total de patentes depositadas até o ano de 2014. A partir dos documentos disponibilizados pela agência, foi possível criar uma lista com os inventores das 320 patentes depositadas até 2014 bem como verificar a relação de cada inventor com a quantidade de depósitos realizados.

Tendo em vista o elevado número de inventores (587 no total), foi necessário realizar um corte para a seleção dos entrevistados. Sendo assim, o segundo critério se deu a partir da escolha de inventores docentes-pesquisadores que depositaram seis ou mais patentes. Esse número foi definido porque, a partir de 5 ou menos depósitos, havia uma grande quantidade de inventores, o que impossibilitaria a realização das entrevistas considerando as limitações de tempo do processo de pesquisa. Dos inventores de 6 ou mais patentes, identificou-se potencialmente 22 docentes-pesquisadores da UFPR a ser entrevistados.

A partir de agosto de 2015, foi encaminhado um e-mail solicitando uma entrevista formal. Para os docentes-pesquisadores que não responderam o e-mail, foi realizada uma segunda tentativa duas semanas após o envio do primeiro e-mail. Considerando os procedimentos, cabe ressaltar que, dos 22 docentes contatados, $13(59,09 \%)$ responderam e confirmaram a solicitação de entrevista. Assim, após a etapa descrita anteriormente, realizou-se o agendamento das entrevistas entre os meses de agosto e outubro de 2015, as quais foram efetuadas geralmente no local de trabalho (laboratórios) ou na sala dos docentes-pesquisadores. 
Tabela 1

Entrevistas e Observações Realizadas no Estudo de Caso

\begin{tabular}{clccc}
\hline Entrevista & Departamento/Função/Evento & $\begin{array}{c}\mathbf{N}^{\mathbf{0}} \text { de } \\
\text { Depósitos }\end{array}$ & \% Total & $\begin{array}{c}\text { Tempo } \\
\text { Total }\end{array}$ \\
\hline P1 & Bioprocessos e Biotecnologia & 41 & $12,81 \%$ & 21 minutos \\
P2 ${ }^{\text {(a) }}$ & Farmácia & 35 & $10,94 \%$ & 40 minutos \\
P3 & Farmácia & 33 & $10,31 \%$ & 47 minutos \\
P4 & Química & 32 & $10,00 \%$ & 31 minutos \\
P5 & Farmácia & 25 & $7,81 \%$ & 17 minutos \\
P6 & Química & 17 & $5,31 \%$ & 24 minutos \\
P7 & Física & 11 & $3,44 \%$ & 65 minutos \\
P8 & Bioquímica e Biologia Molecular & 10 & $3,13 \%$ & 42 minutos \\
P9 & Engenharia Mecânica & 9 & $2,81 \%$ & 19 minutos \\
P10 & Física & 8 & $2,50 \%$ & 50 minutos \\
P11 & Química & 8 & $2,50 \%$ & 59 minutos \\
P12 & Química & 7 & $2,19 \%$ & 10 minutos \\
P13 & Química & 6 & $1,88 \%$ & 16 minutos \\
E1 & Díretor da AI e Coordenador de PI e TT & - & - & 60 minutos \\
E2 & Coordenador de PI e TT & - & - & 58 minutos \\
E3 & Ex-Diretora da Agência de Inovação & - & - & 73 minutos \\
E4 & Conselheira da resolução 01/2015 e 02/2015 do COUN & - & - & 10 minutos \\
O1 & Apresentação da AI aos estudantes & - & - & 76 minutos \\
O2 & Workshop de Propriedade Intelectual & - & - & 170 minutos \\
\hline
\end{tabular}

Nota. Fonte: Elaborada pelos autores.

(a) Gravação de áudio não permitida pelo entrevistado.

Constatou-se que, apesar dos 13 docentes-pesquisadores representarem apenas 2,22\% dos inventores, esses foram centrais na experiência de patenteamento da universidade, pois tiveram participação em 160 depósitos realizados, ou seja, 50\% do total das patentes depositadas (320) pela universidade até o ano de 2014, o que confirma a centralidade de sua participação.

Todos os docentes-pesquisadores entrevistados são adjuntos ou titulares da Universidade Federal do Paraná, com, no mínimo, titulação de Doutorado em sua área. Entrevistaram-se 5 docentespesquisadores do departamento de química, 3 do departamento de farmácia, 2 do departamento de física, e 1 no departamento de Bioprocessos e Biotecnologia, 1 em Bioquímica e Biologia Molecular e 1 em Engenharia Mecânica.

As entrevistas, juntamente com as observações, totalizaram 888 minutos e foram gravadas e transcritas para posterior análise de dados. A elaboração dos questionários para a realização das entrevistas semiestruturadas, tanto para os gestores quanto para os pesquisadores, seguiu as diretrizes do protocolo de estudo de caso apontadas por Yin (2015). As perguntas específicas aos entrevistados derivaram das questões gerais do estudo com base no referencial teórico utilizado. No que diz respeito à coleta de documentos, foram divididos em documentos da Agência da Inovação da UFPR, Leis e Resoluções, Livros e Publicações, Notícias e Vídeos. 
Na análise dos dados, utilizou-se a técnica de análise de conteúdo temática (Bardin, 2010). Dessa forma, este estudo seguiu os passos metodológicos fornecidos pela autora, que divide a análise de conteúdo em três principais etapas: (a) pré-análise; (b) exploração do material; e (c) tratamento dos resultados, inferência e interpretação. Para a constituição do corpus, optou-se pela regra da pertinência, pela qual os documentos devem adaptar-se ao conteúdo e aos objetivos da pesquisa. Na fase de exploração, utilizou-se o software ATLAS.ti v.6 para a codificação e o tratamento do corpus coletado. Também foram adotados dois principais tipos de triangulação de dados: (a) triangulação de fontes de evidência simples, que busca comparar os dados de diferentes fontes de evidências realizadas por uma mesma técnica (ex: entrevistas); e (b) triangulação das informações obtidas por meio das diversas técnicas de coleta de dados, que os compara entre diferentes tipos de técnicas (ex: entrevista, pesquisa documental e observação).

\section{Descrição do Caso de Transferência Tecnológica na Agência de Inovação da UFPR}

As ações voltadas à gestão da transferência tecnológica dentro da Universidade Federal do Paraná originaram-se de maneira desintegrada inicialmente. A fundação do NEMPS (incubadora de empresas) em 2001 foi uma das primeiras ações nesse sentido. O núcleo foi criado com o propósito de dar suporte à criação de empresas inovadoras e disseminar o empreendedorismo, principalmente na esfera da universidade.

Posteriormente, entre os anos de 2002 e 2003, diversas parcerias foram feitas entre instituições no Estado do Paraná (APPI/TECPAR, UFPR, CEFET-PR, PUC-PR e Fundação Araucária), com o objetivo de aperfeiçoar a disseminação da cultura de propriedade intelectual no estado. Entre o final de 2002 e o início de 2003, por meio do auxílio de recursos oriundos de editais do Fundo Verde-Amarelo, criou-se a Rede Paranaense de Propriedade Industrial, em conjunto com a Agência Paranaense de Propriedade Industrial (APPI/TECPAR). Além da disseminação da cultura de propriedade intelectual, o intuito também era de fomentar a criação de núcleos de propriedade intelectual e realizar a integração desses núcleos.

No âmbito da universidade, houve feitos em relação ao assunto, principalmente a partir da iniciativa de gestores vinculados à Pró-reitoria de Pesquisa e Pós-graduação. O principal resultado dessas ações foram a elaboração e a aprovação da resolução n. 09 (2003) do Conselho Universitário, que regulamentou a proteção de direitos relativos à propriedade industrial e intelectual na esfera da UFPR e, posteriormente, a criação do Núcleo de Propriedade Intelectual (NPI) por meio dos recursos do edital que originou a Rede Paranaense de Propriedade Industrial.

A partir da instituição da Lei da Inovação, em 2004, e também de novos estímulos e investimentos governamentais para a criação dos Núcleos de Inovação Tecnológica - com recursos provenientes do Fundo Verde-Amarelo - em parceria, novamente, com o TECPAR/APPI e o CEFET-PR, houve a possibilidade de reestruturação e expansão das atividades realizadas pelo NPI. Desse modo, criou-se, em 2005, o Escritório de Transferência de Tecnologia. As melhorias, a partir dos investimentos recebidos pelo ETT, possibilitaram a ampliação de sua estrutura e também o fomento e o desenvolvimento de novas parcerias por intermédio de eventos, informativos, e também da criação de catálogos dos laboratórios e dos projetos de pesquisa dentro da universidade.

Paralelamente, ao longo dos anos, outros acontecimentos significativos relacionados à inovação no país e no Estado do Paraná ocorreram, como a criação do Fórum Nacional de Gestores de Inovação e Transferência Tecnológica (FORTEC), em 2006, e a abertura da Rede de Núcleos de Inovação Tecnológica e Empreendedorismo do Paraná (NITPAR), em 2007.

Entretanto, embora a resolução n. 09 (2003) do COUN regulamentasse a proteção de propriedade intelectual, não existia, no âmbito da universidade, um mecanismo que legitimasse a atuação do ETT, de acordo com as disposições da Lei da Inovação (Lei n. 10.973, 2004) e do Decreto n. 5.563 (2005). 
Nesse sentido, em conjunto com a necessidade de integrar as atividades de incubação de empresas às de propriedade intelectual e transferência tecnológica, a Agência de Inovação Tecnológica da Universidade Federal do Paraná (AGITEC) foi instituída em 28 de maio de 2008, e, após, aberta em 2009 (Figura 3).

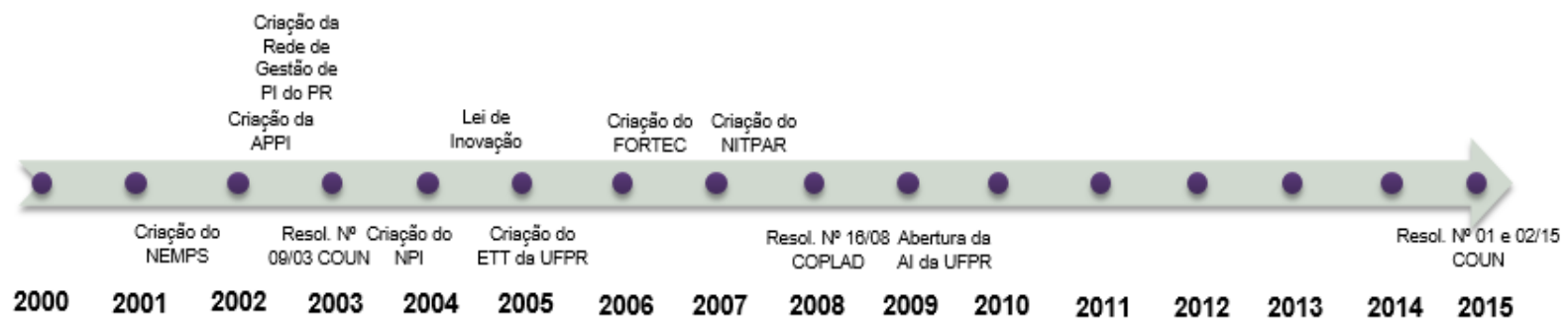

Figura 3. Linha do Tempo das Ações Voltados à Transferência de Tecnologia

No ano de 2015, ocorreu a necessidade de atualização dos regimentos de propriedade intelectual da universidade já que a Resolução n. 09 (2003) do COUN não comportava as especificidades da Lei de Inovação. Dessa forma, desenvolveram-se, na esfera da universidade, as questões referentes à transferência de tecnologia por meio das resoluções $n^{\circ} 01$ e 02 (2015) do Conselho Universitário (COUN), possibilitando o alinhamento entre as normas da universidade e as instituídas para atuação dos NITs.

Atualmente, de acordo com o Ranking de Universidades, da Folha de São Paulo, a Universidade Federal do Paraná (UFPR) é reconhecida como a $4^{\circ}$ universidade mais inovadora do país, atrás apenas da Universidade de São Paulo, da Universidade Estadual de Campinas e da Universidade Federal de Minas Gerais.

\section{Análise dos intervenientes do processo de transferência tecnológica}

Os intervenientes do processo de transferência tecnológica são caracterizados enquanto barreiras, facilitadores e motivadores que afetam o desempenho dos ETTs em diferentes níveis de análise. Nesse sentido, foram analisados os intervenientes relacionados à Agência de Inovação da UFPR e individuais (pesquisadores). Também foram identificados, durante o processo, coleta de dados, barreiras relacionadas aos aspectos de gestão da universidade para além dos fatores do ETT e pesquisadores.

\section{Barreiras e facilitadores relacionados à agência de inovação da UFPR}

Foram identificados barreiras e facilitadores desse processo. Essas variáveis fornecem indícios qualitativos dos fatores que impedem ou contribuem para o efetivo desempenho do ETT da UFPR. A sequência desses fatores (facilitadores e barreiras) está elencada de acordo com a frequência de aparecimento no campo empírico, principalmente a partir da codificação das falas dos sujeitos entrevistados (gestores da agência de inovação e pesquisadores da universidade) e de outras evidências.

\section{Barreiras do processo de transferência tecnológica}

Uma das barreiras identificadas no processo de transferência tecnológica está no processo de redação das patentes. A Agência de Inovação da UFPR atualmente não dispõe de profissionais especializados para a busca de anterioridade e redação da patente, sendo que a responsabilidade é transferida aos pesquisadores da universidade.

Contudo, conforme Garnica e Torkomian (2009), esse processo requer profissionais com grande especialização nas mais diversas vertentes do conhecimento, e são necessárias adaptações de linguagem e conhecimento jurídico (Closs et al., 2012), pois se difere em vários aspectos das publicações de artigos científicos (papers), resumos e painéis. Nesse sentido, tanto a busca de anterioridade da patente quanto sua redação, se deixados a cargo dos pesquisadores, as chances de indeferimento do pedido de depósito 
de patente são potencializadas, o que interfere negativamente nos resultados de depósito de patentes realizados pelo ETT.

Nesse entendimento, os entrevistados E2 e E3 têm consciência desse entrave relacionado ao processo de redação de patentes e enfatizam que o sistema é falho dentro da universidade, e que algumas patentes depositadas em anos anteriores estão voltando com os pareceres técnicos pelo INPI constatando que não há nestas atividade inventiva, um dos requisitos básicos para a patente ser concedida.

Os pesquisadores também demonstram preocupação em relação a esse processo. Os entrevistados P4, P5, P8, P10, P11 e P13, de forma geral, relatam sobre a questão da possibilidade da patente ser indeferida, pois reconhecem tanto suas limitações ao redigir a patente quanto a ausência de suporte especializado, embora algumas ações adotadas pelos gestores da Agência tenham auxiliado os pesquisadores da universidade a melhorarem suas redações.

A segunda barreira identificada no processo de transferência tecnológica está relacionada ao capital humano do ETT. Parte do quadro de funcionários é estruturada por meio de estagiários ou bolsistas, causando a rotatividade de funcionários do ETT. Isso é percebido como uma questão negativa em diversos estudos sobre ETTs (Desidério \& Zilber, 2014; Dias \& Porto, 2013; Silva et al., 2013).

De acordo com relatos dos entrevistadores E2, P3, P8 e P11, esses bolsistas ou estagiários chegam com nenhum ou algum conhecimento/experiência sobre transferência tecnológica, aprendem os processos, realizam cursos, capacitações, mas, devido ao tempo máximo (geralmente dois anos) estabelecido em contrato, vão embora e levam todo o aprendizado que obtiveram dentro da Agência, necessitando dispor de tempo e recursos para capacitar outros estagiários e bolsistas novamente.

Os obstáculos entre acadêmicos e empresários também são caracterizados principalmente pelas divergências dos aspectos relacionados à cultura do ambiente em que estão inseridos (Siegel et al., 2003). A fala do pesquisador P3 auxilia em parte a ilustrar esse aspecto: "Bom pesquisador geralmente não é um bom vendedor". Nesse sentido, os ETTs atuam como agentes duplos (O'Kane et al., 2015), capazes de criar pontes entre as fronteiras da academia e da indústria. Dentro desse aspecto, identificase a terceira barreira, que é a falta de mecanismos de apoio à interação universidade-empresa pelo ETT, entre pesquisadores e empresários.

Os pesquisadores, no geral, desconhecem elementos sobre o processo de negociação e os mecanismos capazes de transformar suas descobertas em produtos e processos comercializáveis. Embora haja ações voltadas a promover essa interação, alguns pesquisadores relatam que ainda se sentem distantes da realidade da indústria e percebem que o ETT não tem estabelecido um canal efetivo para que as parcerias ocorram. Essa barreira também é identificada em outros ETTs, como no caso dos estudos de Desidério e Zilber (2014), Closs et al. (2012) e Garnica e Torkomian (2009).

A Agência de Inovação da UFPR também não dispõe de recursos para a realização do patenteamento internacional. Assim como identificado nos estudos de Dias e Porto (2014), essa quarta barreira identificada impede que o potencial tecnológico desenvolvido pelos pesquisadores seja divulgado, produzido e comercializado em mercados externos ao Brasil. 
Tabela 2

Evidências Relacionadas às Barreiras no Escritório de Transferência Tecnológica

\begin{tabular}{ll}
\hline Barreiras & Evidências \\
\hline $\begin{array}{l}\text { Processo de Redação } \\
\text { da Patente }\end{array}$ & $\begin{array}{l}\text { E2: "Então, pra gente corrigir esse processo, necessariamente tem que ter uma } \\
\text { qualidade na busca e redação, coisa que hoje a gente não oferece aos pesquisadores.... } \\
\text { não sabem como fazer [referindo-se à redação da patente pelos pesquisadores]. A } \\
\text { qualidade é discutível." }\end{array}$ \\
\cline { 2 - 2 }
\end{tabular}

P10: "no momento que a pessoa vê que ela pode escrever qualquer coisa, dentro do padrão, vai ser depositada, e ela vai depositar no currículo, isso pode virar um problema.... uma pessoa que não tenha um cuidado, ela pode escrever qualquer coisa."

P13: "você pode patentear de tudo, você não tem o peso julgamento. Se publicar um paper, seu paper passa por gente especializada que vai julgar ... a patente, se eu quiser patentear, sei lá, tá depositado ... daqui dez anos até a concessão, daqui dez anos, 'ah não vai ser concedido', tá bom, mas por dez anos, eu contei pra todo mundo que eu tinha feito uma patente."

Capital Humano do E2: "Enquanto a gente não tiver cargos específicos na universidade, de analista, de ETT propriedade intelectual, especialista em cada área que tenha condições de dar suporte técnico, não adianta vir bolsista, não adianta vir estagiários que se especializam, porque quando eles tiverem prontos, eles vão sair. Não há tempo suficiente. "

P11: "Uma das coisas que eu vejo de ruim é que eles têm muitos estagiários lá no escritório, então cada vez é um menino novo que tá por lá. E aí, sabe, a história vai se perdendo, então você manda um documento, daí o menino diz que não é esse, que é um outro, porque tá sempre mudando."
Mecanismos de Apoio P3: "Bom pesquisador geralmente não é um bom vendedor. Se fosse não estaria aqui. Então, eu acho que pra nós falta essa ferramenta, de negociação. A Agência tem promovido alguns encontros da indústria com os detentores das patentes, mas ainda é algo muito genérico. "

P5: "Talvez esteja faltando realmente essa ponte com as empresas, né? Talvez que existam mecanismos para ajudar a agência de inovação. Que ela consiga fazer essa ligação."

\begin{tabular}{ll}
\hline Patenteamento & P3: "Uma coisa que a universidade está pecando, que essa semana fiquei morren \\
Internacional & de inveja, o jornal das 7 lá o [universidade X] lança sua primeira patente \\
& internacional. Nós não temos recursos para o patenteamento internacional. Nós \\
& estamos pecando."
\end{tabular}

Nota. Fonte: Elaborada pelos autores.

A partir dos dados analisados, também foi possível encontrar duas principais barreiras, em relação à universidade, que afetam o desempenho dos ETTs: a burocracia universitária e a ausência de suporte/incentivo por parte desta. A. Ferreira et al. (2013) identificaram a burocracia excessiva da universidade como barreira à interação entre universidade e empresas. Isso porque os processos ocorridos dentro das universidades públicas brasileiras são caracterizados pelo excesso de formalizações, procedimentos e autorização para realização de suas atividades.

Neste contexto, Santana e Porto (2009), em seu estudo, também identificaram a burocracia universitária como um fator que impede a transferência tecnológica, ressaltando a rigidez das regulamentações e a demora para a assinatura dos convênios com empresas.

No caso da UFPR, o entrevistado P8 relata que, para a realização do depósito da patente em parceria com outra instituição ou empresa, é necessária a celebração de um convênio que é gerido por outra unidade da universidade (CRI), e afirma que o processo para iniciação é demorado, pois também são necessárias aprovações de diversas instâncias da universidade. A pesquisadora P5, a partir da sua 
experiência em outras instituições públicas, possui a percepção de que esse não é um problema apenas da UFPR, mas faz parte da realidade da esfera pública no país. Já o pesquisador P6 relata que os docentes são encarregados de preencher diversos relatórios, até mesmo para as atividades mais simples de pesquisa, como a iniciação científica.

Identificou-se como segunda barreira referente à universidade o fato de que não existe apoio nem suporte/incentivo adequados em relação às atividades de transferência tecnológica pelos gestores da universidade, corroborando com o estudo de A. Ferreira et al. (2013), no qual os pesquisadores afirmam também existir a falta de mecanismos e incentivos no âmbito da universidade para transferência tecnológica.

Os entrevistados mencionaram que não existem incentivos/mecanismos para a produção de patentes. A entrevistada E3 afirma que a parte de gestão dentro da universidade é mais valorizada em termos de pontuação para a progressão de carreira e, por isso, existe o interesse de realizar outras atividades do que engajar-se no processo de patenteamento.

Ainda nesse contexto, sob o ponto de vista do pesquisador P3, o processo de patenteamento é mais trabalhoso, contudo, é menos pontuado que o artigo científico, sendo que o pesquisador precisa assegurar a publicação do artigo científico para realizar o pedido de depósito da patente. Nesse sentido, a maioria dos entrevistados concorda que não há valorização de patentes na esfera da universidade.

\section{Facilitadores do processo de transferência tecnológica}

Foi possível constatar, a partir da percepção dos entrevistados, melhoras na aproximação entre pesquisadores e ETT, e também maior profissionalização dos processos relativos à transferência tecnológica. Essa questão foi salientada pelos pesquisadores, principalmente após a criação da Agência de Inovação. A competência dos gestores foi um facilitador que ficou evidente a partir dos relatos transcritos, fator esse não previsto nas pesquisas sobre Escritórios de Transferência Tecnológica.

O pesquisador P1 afirma que não observa dificuldades quanto à efetivação do depósito de suas patentes, e utiliza qualificadores como receptividade, agilidade e proatividade. $\mathrm{O}$ entrevistado P3 informa que os gestores têm auxiliado, apoiado (P8) e que há profissionalismo por parte da Agência. O pesquisador P5 salienta a questão de se atender prontamente, e o P6 fala em bom trabalho, pessoal solícito. O entrevistado P9 menciona os quesitos eficiência, organização, auxílio, enquanto o P10 compreende que a transição para a Agência foi transparente. Já o P13 fala em profissionais e atenciosos. Todas as expressões mencionadas possibilitam reforçar que, embora haja limitações verificadas em relação a alguns processos da Agência de Inovação, os pesquisadores, de forma geral, percebem que os gestores têm facilitado o processo de transferência tecnológica dentro da universidade.

Um segundo aspecto que foi percebido como relevante pelos entrevistados e que facilitou o processo de transferência tecnológica foi a terceirização do processo de redação da patente. Como mencionado na primeira barreira sobre a Agência de Inovação, esse processo possui algumas limitações dentro da universidade. Contudo, no ano de 2014, por meio de recursos do edital da Fundação Araucária, a agência contratou uma empresa para efetivar esse processo.

A contratação da empresa especializada em redigir a patente foi percebida como positiva pelos pesquisadores que realizam o patenteamento. Os entrevistados E2, P3, P4, P5, P7, P8 e P10 relatam que perceberam melhora na qualidade, tanto na busca de anterioridade quanto da redação de patente. Essa constatação corrobora com o estudo de Santana e Porto (2009), de que a contratação de escritórios para redação torna o processo mais ágil e eficiente.

Outra questão identificada como facilitador foi divulgação e disseminação da cultura de PI. Assim como constatado no estudo de G. C. Ferreira et al. (2012), esse trabalho é significativo para o aumento das atividades de transferência tecnológica dentro da universidade. 
Neste âmbito de explanações, cabe ressaltar que os entrevistados E2 e E3 perceberam que, após as divulgações sobre o trabalho realizado pela Agência de Inovação, os pesquisadores passaram a procurar pelos seus serviços, principalmente sobre as questões referentes ao depósito de patentes. A entrevistada E3, que coordenou a área PI nos anos iniciais da Agência, relata que, mesmo com grandes restrições de recursos e funcionários, acredita que a divulgação por meio de folders, boca a boca e a participação em eventos despertaram o interesse de muitos pesquisadores. Já os pesquisadores P4, P8, P11 relataram experiências positivas em relação a esse aspecto.

Tabela 3

Evidências Relacionadas aos Facilitadores no Escritório de Transferência Tecnológica

\begin{tabular}{|c|c|}
\hline Facilitadores & Evidências \\
\hline \multirow[t]{3}{*}{ Competência dos Gestores } & $\begin{array}{l}\text { P1: "a gente não tem dificuldade nenhuma, a gente contata o escritório de } \\
\text { inovação lá, as pessoas são muito receptivas, são muito ágeis e todas as patentes } \\
\text { são depositadas." }\end{array}$ \\
\hline & $\begin{array}{l}\text { P5: "Muitas vezes a gente entrou em contato com o [coordenador de PI e TT]. } \\
\text { Tudo que a gente precisou, eles sempre atenderam a gente prontamente, não teve } \\
\text { problema nenhum." }\end{array}$ \\
\hline & $\begin{array}{l}\text { P8: "Um diferencial também que ajudou muito foi a Agência de Inovação. Todo } \\
\text { assessoramento que a gente não tinha experiência. Então todo esse processo que a } \\
\text { gente iniciou em 2010-2011, contou com o apoio da Agência de Inovação, nesse } \\
\text { processo de fazer depósito de patente." }\end{array}$ \\
\hline \multirow[t]{2}{*}{ Terceirização da Redação } & $\begin{array}{l}\text { E2: "A gente teve um piloto no ano passado. Nós contratamos uma empresa por } \\
\text { meio de um edital da Fundação Araucária. A experiência foi excelente, deu } \\
\text { resultado, deu fruto, redações com qualidade. Pesquisadores que entenderam } \\
\text { melhor a formatação de uma redação, mas infelizmente os recursos acabaram e o } \\
\text { projeto encerrou ali." }\end{array}$ \\
\hline & $\begin{array}{l}\text { P7: "Então, são duas situações que eu vou colocar como relevante: uma foi do } \\
\text { edital de busca e de correção das patentes. Que foi um edital que tinha dinheiro } \\
\text { acho que da fundação Araucária e que realmente as patentes ficaram muito mais } \\
\text { caprichadas, muito mais redondinhas." }\end{array}$ \\
\hline \multirow[t]{2}{*}{$\begin{array}{l}\text { Disseminação da Cultura } \\
\text { de PI }\end{array}$} & $\begin{array}{l}\text { E3: "O meu caso lá, a minha parte era incentivar a proteção dos ativos. Eu acho } \\
\text { que modéstia a parte a propaganda boca a boca, que a gente não tinha recursos, a } \\
\text { gente não tinha marqueteiro, a gente não tinha comunicação a gente não tinha } \\
\text { nada. Com poucos recursos e essa propaganda boca- a boca que eu acho que } \\
\text { funciona muito, graças a isso que os professores vinham na minha porta pra } \\
\text { querer saber." }\end{array}$ \\
\hline & $\begin{array}{l}\text { P8: "A gente foi atrás da agência. Até na época eu era coordenador de pós- } \\
\text { graduação, foi muito bom, que eu convidei, veio o professor [ex-diretor da } \\
\text { agência], o [coordenador de PI e TT], ministraram uma palestra, com os alunos } \\
\text { da pós-graduação." }\end{array}$ \\
\hline
\end{tabular}

Nota. Fonte: Elaborada pelos autores.

\section{Motivadores, barreiras e facilitadores relacionados aos pesquisadores}

Entre as questões que motivam os pesquisadores entrevistados a envolver-se com a proteção de suas descobertas na universidade identificou-se a consciência de proteção. Esse é um aspecto que não havia sido verificado na literatura anteriormente, mas que apareceu de forma expressiva neste estudo de caso.

A maior parte dos entrevistados compreendem seu papel institucional dentro da universidade e que seus esforços não estão voltados apenas aos interesses individuais ou do seu grupo de pesquisa, mas 
estão imersos dentro de um contexto social significativo para o pesquisador, o que os motiva a engajarse no processo de transferência tecnológica (principalmente na proteção de suas descobertas).

Os entrevistados possuem consciência de que estão gerando resultados para a sociedade e que esses vão além dos desenvolvidos na esfera da universidade por meio dos trabalhos de docência (ministrar aulas, palestras) e pesquisa (publicação de artigos, projetos de extensão e etc.). A consciência de proteção é evidenciada na fala dos entrevistados P1, P3, P4, P5, P7, P8, P10, P11 e P13.

Um segundo motivador identificado e que corrobora os estudos de D'Este e Perkmann (2011), Closs et al. (2012) e Noveli e Segatto (2012) refere-se ao acesso a recursos para pesquisa e ganhos econômicos. Alguns pesquisadores possuem interesse em que suas patentes ou pesquisas tragam, de alguma forma, resultado financeiro ou material para seu laboratório ou para si. Outros entrevistados relatam também a motivação de obter ganhos econômicos para si, provenientes dos resultados gerados pelo licenciamento. Conforme disposto no Art. 13 da Lei da Inovação, é garantido aos criadores entre $5 \%$ a $1 / 3$ dos ganhos auferidos pela ICT dos resultados dos contratos de transferência de tecnologia.

Por fim, um terceiro motivador que apareceu de forma menos explícita nas entrevistas está relacionado ao prestígio acadêmico. Os pesquisadores P8 e P11 compreendem que o envolvimento com o patenteamento é algo que possui impacto nos seus currículos, corroborando com o estudo de Baldini, Grimaldi e Sobrero (2007), que afirmam que os pesquisadores se envolvem com o patenteamento para aumentar seu prestígio e reputação acadêmica. Tais achados vão em oposição ao estudo de Derrick (2015), que identificou que os pesquisadores são mais motivados pela carreira do que pelo financiamento. Tal questão talvez se dê pela característica do financiamento de pesquisa no Brasil, que, além de ser em grande parte oriundo de recursos públicos, também está atrelado ao próprio currículo do pesquisador.

Tabela 4

Evidências Relacionadas aos Motivadores dos Pesquisadores

\begin{tabular}{ll}
\hline Motivadores & Evidências \\
\hline Consciência de & P3: "“Eu tenho o entendimento que uma pesquisa pública, de uma universidade \\
Proteção & $\begin{array}{l}\text { pública, feita com o dinheiro do povo, ela tem que ser resguardada, tem que ser } \\
\text { protegida.... Eu entendo que o patenteamento é uma questão de soberania nacional." }\end{array}$ \\
\cline { 2 - 2 }
\end{tabular}

P5: "Proteção pra pesquisa brasileira. Hoje as grandes empresas multinacionais, elas estão atrás, né? De... digamos assim, de pesquisas promissoras, que podem levar ao descobrimento de alguma coisa nova."

\footnotetext{
Acesso a Recursos e P6: "a gente quer muito poder da uma bolsa pro estudante, ter a tranquilidade de Ganhos Econômicos fazer uma pesquisa e ter um dinheirinho pra fazer as coisas no laboratório que é muito difícil ter."
}

P10: "o meu objetivo é fazer coisas que sirvam, e se isso produzir dinheiro pra mim e pra universidade está ótimo."

Prestígio Acadêmico P8: "É, a área de biotecnologia tem esse retorno também né, ou seja, o depósito de patente é um produto, é uma produção bibliográfica importante, né. Assim como a publicação de artigos científicos, na área de biotecnologia é valorizado o depósito de patentes."

P11: "Ter uma patente ou é de alguma forma algum retorno financeiro, ou de alguma forma é enriquecimento do currículo pessoal, né."

Nota. Fonte: Elaborada pelos autores.

No que se refere às barreiras relacionadas aos pesquisadores, de acordo com Borsoi (2012), o ofício de pesquisa e docência nas universidades públicas federais é caracterizado pela sobrecarga de trabalho e por altas exigências no cumprimento de metas produtivistas. Essa questão também pôde ser identificada e entende-se que a sobrecarga de atividades por parte do pesquisador é um fator que afeta 
o processo de transferência tecnológica dentro da universidade. Os estudos de Chais et al. (2013), A. Ferreira et al. (2013), Closs et al. (2012) e Santana e Porto (2009) concordam nesse aspecto em diversos pontos.

Os entrevistados, no geral, relatam sobre a multifuncionalidade ao qual estão submetidos no âmbito acadêmico, o que afeta seu envolvimento com o processo de transferência tecnológica. Os entrevistados P3, P5, P7, P8 e P11 afirmam que estão envolvidos tanto com a graduação quanto com a pós-graduação, e que, dentro dessas duas vertentes, estão envolvidos com extensão, orientações, projetos, reuniões de colegiado, plenárias, atividades administrativas como o preenchimento de relatórios, pareceres, prestação de contas, entre outras atividades. Pelo fato de o patenteamento ser percebido como algo secundário dentro da esfera acadêmica, devido à falta de tempo (o que é relatado frequentemente pelos entrevistados), não se envolvem com algumas atividades organizadas pela Agência de Inovação.

Além disso, estudos têm demostrado que muitos pesquisadores não possuem experiência ou desconhecem os mecanismos de transferência tecnológica e de negociação da universidade (A. Ferreira et al., 2013; Garnica \& Torkomian, 2009). Nesse sentido, a partir da fala dos respondentes, foi possível identificar que desinteresse e desconhecimento dos pesquisadores sobre o processo de transferência tecnológica são também barreiras do processo neste estudo de caso.

Dessa forma, desconhecimento e desinteresse são caracterizados pelo fato de os pesquisadores não conhecerem o processo de TT ou saberem que este existe e, no entanto, não se engajarem nele. A limitação reside também no desconhecimento, tanto sobre o processo de negociação quanto sobre a existência da Agência de Inovação. O entrevistado E2 afirma serem raros os grupos de pesquisadores que conheciam a Agência, embora isso tenha melhorado com a divulgação da PI dentro da universidade. Os pesquisadores relatam que não sabem como realizar negociações com empresas e que não possuem vocação para isso. Algumas questões mais específicas também são identificadas, como o pesquisador P13 que afirma que possui preguiça de patentear, pois entende que processo de patenteamento é trabalhoso e leva tempo, ou de professores que optam apenas por realizar publicações ou envolver-se com as questões de docência.

Tabela 5

Evidências Relacionadas às Barreiras Enfrentadas pelos Pesquisadores

\begin{tabular}{ll}
\hline Barreiras & Evidências \\
\hline Sobrecarga de Atividades & $\begin{array}{l}\text { P5: "E o professor, hoje, ele é multifuncional. Então a gente tem que se dedicar } \\
\text { à graduação, se dedicar à pós-graduação, tem que ter um pouco de extensão e } \\
\text { ainda lidar com essa parte burocrática. Não é muito fácil não. Aí pede muita } \\
\text { coisa, relatórios, prestação de contas, sem falar que a gente tem projetos de } \\
\text { CNPq que a gente tem que prestar contas, fazer orçamento, fazer não sei o quê. } \\
\text { Aí o tempo pra encontrar uma empresa já era. E até existe essa burocratização, } \\
\text { né, da universidade. E não é tão fácil fazer um convênio assim." }\end{array}$ \\
\hline
\end{tabular}

P8: "Mais uma coisa: a gente não tem tempo hábil, porque a gente tem que ler as teses dos alunos, corrigir, fazer a publicação... Tempo, tempo mesmo... literalmente, não tem tempo."

Desconhecimento e Desinteresse
P3: "E outra coisa que eu tenho sentido, principalmente no meu grupo de trabalho aqui na minha redondeza, muitos professores não entendem o real valor da patente e não valorizam."

P6: "Desconhecimento, desinteresse, afastamento da questão tecnológica, visão acadêmica maximizada. Tem muitos colegas meus desse departamento e de outros que condenam a pesquisa tecnológica, dizendo que a pesquisa afasta a universidade de seus verdadeiros propósitos. Tem um pouco de tudo. $\mathrm{Na}$ verdade, é uma pena."

Nota. Fonte: Elaborada pelos autores.

RAC, Rio de Janeiro, v. 21, n. 4, art. 1, pp. 435-457, Julho/Agosto, 2017, www.anpad.org.br/rac (oc) E 
No que diz respeito aos facilitadores, considerando a opinião dos pesquisadores, foi possível verificar que a experiência acadêmica é um aspecto relevante. Ao questionar os pesquisadores que mais patentearam, percebeu-se que a maior parcela já possuía muitos anos de vínculo com a universidade, como também o contato com as questões de patenteamento.

Nesse sentido, Wu et al. (2015) afirmam que estudos têm demonstrado que, no nível de análise individual, tanto a percepção dos pesquisadores quanto suas experiências explicam a predisposição de se envolverem em atividades de comercialização. Desse modo, geralmente os cientistas mais experientes estão mais propensos a envolver-se com as atividades de patenteamento, pois atingiram certo grau de segurança em suas carreiras acadêmicas (Wu et al., 2015).

Vale ressaltar, nesse contexto, que parte dos docentes entrevistados já estava vinculada antes mesmo das ações relacionadas à propriedade intelectual na esfera da universidade, ou alguns, também, já haviam vivenciado experiências internacionais em relação ao depósito de patentes anteriores ao vínculo com a universidade.

Tabela 6

Evidências Relacionadas ao Facilitador dos Pesquisadores

\begin{tabular}{ll}
\hline Facilitador & Evidências \\
\hline Experiência Acadêmica & $\begin{array}{l}\text { P1: "Olha, minha primeira experiência remota, mais de } 20 \text { anos atrás, não existia } \\
\text { nem escritório de inovação." }\end{array}$ \\
\cline { 2 - 2 } & $\begin{array}{l}\text { P4: "Depois de 34 patentes, a gente já tem esse domínio de como redigir as coisas } \\
\text { e, nas últimas, eles simplesmente submetem o que a gente manda." }\end{array}$ \\
\hline $\begin{array}{l}\text { P9: "Na física, tu pode patentear, por exemplo, meu pós-doutorado, foi dentro do } \\
\text { grupo que fica dentro de uma empresa da França, né. Mas o grupo de pesquisa } \\
\text { básica dentro, mas tu tem um cara, um gerente desse grupo que é tipo, tem um } \\
\text { chefão científico e o chefão tecnológico. O chefão tecnológico fica olhando 'o que } \\
\text { nós podemos patentear?', o chefão científico fica procurando descoberta } \\
\text { científica." }\end{array}$ \\
\hline
\end{tabular}

Nota. Fonte: Elaborada pelos autores.

\section{Considerações Finais}

O objetivo desta pesquisa foi o de investigar os intervenientes (barreiras, facilitadores e motivadores) do processo de transferência tecnológica, analisando principalmente aspectos relacionados à propriedade intelectual no âmbito da universidade, ETT e pesquisadores. Verificou-se que a criação da Agência de Inovação da UFPR não ocorreu de forma isolada e independente, e foi determinada por uma sucessão de eventos dependentes da trajetória da universidade. Dessa forma, os estímulos e os financiamentos governamentais de apoio à inovação e as parcerias realizadas com outras instituições em sua região para captação de recursos foram condições significativas para a institucionalização do processo de transferência tecnológica. $\mathrm{O}$ estudo possibilitou respaldar trabalhos anteriores descritos na literatura, e também ampliá-los, como no caso da competência dos gestores da Agência de Inovação enquanto fator facilitador, e do motivador de consciência de proteção por parte dos pesquisadores.

Identificaram-se barreiras no ETT, como o processo de redação da patente, o quadro reduzido de funcionários, a rotatividade, a carência de mecanismos de interação entre universidade e empresas, e obstáculos relacionados ao patenteamento internacional. Tais evidências vão ao encontro das barreiras já verificadas nos estudos de Closs et al. (2012), Desidério e Zilber (2014), Dias e Porto (2013, 2014), Garnica e Torkomian (2009), Santana e Porto (2009) e Silva, Kovaleski e Gaia (2013). Assim, tais restrições ocorrem, em parte, pela falta de apoio e estrutura da universidade ao ETT e pesquisadores e 
pela burocracia interna, fatores esses também identificados como barreiras em outras universidades (A. Ferreira et al., 2013; Santana \& Porto, 2009).

Entre as barreiras relacionadas aos pesquisadores, verificou-se que a sobrecarga de atividades, o desconhecimento e o desinteresse dos pesquisadores, são elementos preponderantes e que afetam negativamente o processo de transferência tecnológica. Tais fatores vão ao encontro dos estudos já mencionados (Closs et al., 2012; Desidério \& Zilber, 2014; Garnica \& Torkomian, 2009; Santana \& Porto, 2009). A falta de incentivo para realização de patenteamento também foi um aspecto observado (Closs et al., 2012).

Os principais facilitadores concernentes ao ETT, por sua vez, estão na competência dos gestores e na disseminação de cultura da propriedade intelectual, corroborando com o estudo de G. C. Ferreira et al. (2012) e também com a experiência de terceirização do processo de redação da patente, questão congruente com os estudos de Dias e Porto (2013), Lucena e Sproesser (2015) e Santana e Porto (2009).

No que diz respeito aos facilitadores dos pesquisadores, examinou-se que a experiência acadêmica dos pesquisadores é um fator relevante para o engajamento na transferência de tecnologia (Wu et al., 2015). Desse modo, os pesquisadores que mais patentearam geralmente já possuíam maior experiência prévia com o patenteamento das descobertas ou já estavam há muitos anos vinculados à universidade e com grupos de pesquisa consolidados. As experiências acadêmicas internacionais também auxiliaram nesse processo.

No âmbito dos motivadores identificados, observou-se que a consciência de proteção foi o mais preponderante entre os pesquisadores entrevistados. Esse foi um dos principais fatores não verificados na literatura acadêmica sobre o tema. No que diz respeito ao acesso a recursos, ganhos econômicos e prestígio acadêmico, encontram-se algumas evidências que vão ao encontro das pesquisas desenvolvidas por Closs et al. (2012), D'Este e Perkmann (2011), Noveli e Segatto (2012) e Santana e Porto (2009).

No que se refere às limitações do estudo, o sigilo da atividade de licenciamento na Agência de Inovação da UFPR e o número limitado de contratos licenciados no âmbito da universidade dificultaram o exame de parte do processo de transferência. Além disso, a atividade de incubação de empresas não foi considerada. Desse modo, ocorreu maior ênfase na atividade de proteção da propriedade intelectual, pois verificou-se que esse foi um dos processos que mais sofreu consequências após a institucionalização da Agência. Analisaram-se apenas alguns fatores internos à universidade, não levando em consideração outros stakeholers, tais como empresas, institutos de pesquisa, universidades, entre outros agentes que se relacionam com o ETT, ou aspectos da localidade em que o ETT está inserido (Berbegal-Mirabent, García, \& Ribeiro-Soriano, 2015).

Para futuros estudos sobre ETTs, sugerem-se algumas questões norteadoras a partir dos achados da pesquisa: (a) investigações que avancem tanto no campo teórico quanto nos aspectos de amplitude sobre a temática (estudos quantitativos); (b) estudos que verifiquem a dinâmica de consolidação e os desafios dos Núcleos de Inovação Tecnológica no cenário Brasileiro, não apenas sob o ponto de vista do aspecto legal; (c) pesquisas que analisem os intervenientes nas atividades de licenciamento, visto que é uma questão pouco explorada nos estudos sobre ETTs.

\section{Agradecimentos}

Gostaríamos de endereçar agradecimentos à CAPES pela bolsa concedida durante o período de desenvolvimento da pesquisa. 


\section{Referências}

Baldini, N., Grimaldi, R., \& Sobrero, M. (2007). To patent or no to patent? A survey of Italian inventors on motivations, incentives and obstacles to university patenting. Scientometrics, 70(2), 333-354. http://dx.doi.org/10.1007/s11192-007-0206-5

Bardin, L. (2010). Análise de conteúdo (5a ed.). Lisboa: Edições 70.

Berbegal-Mirabent, J., García, J. L. S., \& Ribeiro-Soriano, D. E. (2015). University-industry partnerships for the provision of R\&D services. Journal of Business Research, 68(7), 1407-1413. http://dx.doi.org/10.1016/j.jbusres.2015.01.023

Borsoi, I. C. F. (2012). Trabalho e produtivismo: saúde e modo de vida de docentes de instituições públicas de ensino superior. Cadernos de Psicologia Social do Trabalho, 15(1), 81-100. http://dx.doi.org/10.11606/issn.1981-0490.v15i1p81-100

Bozeman, B., Rimes, H., \& Youtie, J. (2015). The evolving state-of-the-art in technology transfer research: revisiting the contingent effectiveness model. Research Policy, 44(1), 34-49. http://dx.doi.org/10.1016/j.respol.2014.06.008

Brescia, F., Colombo, G., \& Landoni, P. (2016). Organizational structures of knowledge transfer offices: an analysis of the world's top-ranked universities. The Journal of Technology Transfer, 41(1), 132-151. http://dx.doi.org/10.1007/s10961-014-9384-5

Chais, C. C., Scopel, A. M., Machado, C. P., \& Oléa, P. M. (2013). Atuação dos núcleos de inovação tecnológica na promoção do desenvolvimento regional a partir da abordagem da tríplice hélice. Revista GUAL, 6(4), 171-189. http://dx.doi.org/10.5007/1983-4535.2013v6n4p171

Closs, L., Ferreira, G., Sampaio, C., \& Perin, M. (2012). Intervenientes na transferência de tecnologia universidade-empresa: o caso PUCRS. Revista de Administração Contemporânea, 16(1), 61-78. Recuperado de http://www.scielo.br/pdf/rac/v16n1/a05v16n1.pdf. http://dx.doi.org/10.1590/S1415-65552012000100005

Cruz, C. H. de B. (2010). Ciência, tecnologia e inovação no Brasil: desafios para o período 2011 a 2015. Revista Interesse Nacional, (10), 1-22. Recuperado de http://www.ifi.unicamp.br/ brito/artigos/CTI-desafios-InteresseNacional-07082010-FINAL.pdf

Decreto n. 5.563, de 11 de outubro de 2005. (2005). Regulamenta a Lei no 10.973, de 2 de dezembro de 2004, que dispõe sobre incentivos à inovação e à pesquisa científica e tecnológica no ambiente produtivo, e dá outras providências. Diário Oficial da União. Brasília, DF: Casa Civil.

Derrick, G. E. (2015). Integration versus separation: structure and strategies of the technology transfer office (TTO) in medical research organizations. The Journal of Technology Transfer, 40(1), 105122. http://dx.doi.org/10.1007/s10961-014-9343-1

Desidério, P. H. M., \& Zilber, M. A. (2014). Barreiras no processo de transferência tecnológica entre agências de inovação e empresas: observações em universidades públicas e privadas. Revista Gestão \& Tecnologia, 14(2), 99-124. http://dx.doi.org/10.20397/g\&t.v14i2.650

D'Este, P., \& Perkmann, M. (2011). Why do academics engage with industry? The entrepreneurial university and individual motivations. Journal of Technology Transfer, 36(3), 316-339. http://dx.doi.org/10.1007/s10961-010-9153-z

Dias, A., \& Porto, G. S. (2013). Gestão de transferência de tecnologia na inova Unicamp. Revista de Administração Contemporânea, 17(3), 263-284. Recuperado de 
http://www.scielo.br/pdf/rac/v17n3/a02v17n3.pdf.

http://dx.doi.org/10.1590/S141565552013000300002

Dias, A., \& Porto, G. S. (2014). Como a USP transfere tecnologia? Organizações \& Sociedade, 21(70), 489-508. http://dx.doi.org/10.1590/S1984-92302014000300008

Eberhart, M. E., \& Pascuci, L. (2014). O processo decisório e suas implicações na cooperação universidade, empresa e governo: um estudo de caso. Revista GUAL, 7(2), 221-242. http://dx.doi.org/10.5007/1983-4535.2014v7n2p221

Eisenhardt, K. M., \& Graebner, M. E. (2007). Theory building from cases: opportunities and challenges. Academy of Management Journal, 50(2), 25-32. http://dx.doi.org/10.5465/AMJ.2007.24160888

Etzkowitz, H. (2003). Research groups as 'quasi-firms': the invention of the entrepreneurial university. Research Policy, 32(1), 109-121. http://dx.doi.org/10.1016/S0048-7333(02)00009-4

Ferreira, A., Amaral, M., \& Leopoldi, M. A. (2013). Análise da interação universidade-empresa sob a perspectiva do corpo docente: um estudo de caso em uma universidade pública. Revista de Administração, Contabilidade e Economia, 12(2), 677-708. Recuperado de http://www.spell.org.br/documentos/download/37576

Ferreira. G. C., Soria, A. F., \& Closs, L. (2012). Gestão da interação Universidade-Empresa: o caso PUCRS. Sociedade e Estado, 27(1), 79-94. http://dx.doi.org/10.1590/S010269922012000100006

Fitzgerald, C., \& Cunningham, J. A. (2016). Inside the university technology transfer office: mission statement analysis. The Journal of Technology Transfer, 41(5), 1235-1246. http://dx.doi.org/10.1007/s10961-015-9419-6

Garnica, L. A., \& Torkomian, A. L. V. (2009). Gestão de tecnologia em universidades: uma análise do patenteamento e dos fatores de dificuldade e de apoio à transferência de tecnologia no Estado de São Paulo. Gestão \& Produção, 16(4), 624-638. http://dx.doi.org/10.1590/S0104$530 \times 2009000400011$

Hayter, C. S., \& Rooksby, J. H. (2016). A legal perspective on university technology transfer. The Journal of Technology Transfer, 41(2), 270-289. http://dx.doi.org/10.1007/s10961-015-9436-5

Huyghe, A., Knockaert, M., Piva, E., \& Wright, M. (2016). Are researchers deliberately bypassing the technology transfer office? An analysis of TTO awareness. Small Business Economics, 47(3), 589-607. http://dx.doi.org/10.1007/s11187-016-9757-2

Kalar, B., \& Antoncic, B. (2015). The entrepreneurial university, academic activities and technology and knowledge transfer in four European countries. Technovation, 36/37, 1-11. http://dx.doi.org/10.1016/j.technovation.2014.11.002

Kaymaz, K., \& Yasin Eryiğit, K. Y. (2011). Determining factors hindering university-industry collaboration: an analysis from the perspective of academicians in the context of entrepreneurial science paradigm. International Journal of Social Inquiry, 4(1), 185-213. Retrieved from http://www.acarindex.com/dosyalar/makale/acarindex-1423904053.pdf

Kruglianskas, I., \& Matias-Pereira, J. (2005). Um enfoque sobre a lei de inovação tecnológica do Brasil. Revista de Administração Pública, 39(5), 1011-1028. Recuperado de www.spell.org.br/documentos/download/12194

Lei n. 10.973, de 2 de dezembro de 2004. (2004). Dispõe sobre incentivos à inovação e à pesquisa científica e tecnológica no ambiente produtivo e dá outras providências. Brasília, DF: Casa Civil. 
Livesey, F. (2014). Report on survey of Brazilian Technology Transfer Offices (TTOs). (Report), Cambridge, UK. University of Cambridge Entreprise. Retrieved from http://www.inova.unicamp.br/sites/default/files/images/FCO_BrazilTTOsurveyReport_0.pdf

Lucena, R. M., \& Sproesser, R. L. (2015). Análise da gestão de licenciamento de patentes: estudo multicasos de instituições federais de ensino superior. Revista de Administração e Inovação, 12(3), 28-55. http://dx.doi.org/10.11606/rai.v12i3.100934

Martins, R. O. (2010). Os núcleos de inovação tecnológica como estratégia das políticas de inovação do MCT (2004-2010). Latin American Journal of Business Management, 3(2), 226-247. Recuperado de http://www.lajbm.net/index.php/journal/article/view/95/60

Muscio, A. (2010). What drives the university use of technology transfer offices? Evidences from Italy. Journal of Technology Transfer, 35(2), 181-202. http://dx.doi.org/10.1007/s10961-009-9121-7

Noveli, M., \& Segatto, A. P. (2012). Processo de cooperação universidade-empresa para a inovação tecnológica em um parque tecnológico: evidências empíricas e proposição de um modelo conceitual. Revista de Administração e Inovação, $9(1), \quad 81-105$. http://dx.doi.org/10.5773/rai.v1i1.610

Núcleo de Inovação Tecnológica do Paraná. (n.d.). Catálogo de patentes. Recuperado de http://nitpar.pr.gov.br/catalogo-de-patentes/catalogo-de-patentes/

O'Kane, C., Mangematin, V., Geoghegan, W., \& Fitzgerald, C. (2015). University technology transfer offices: the search for identity to build legitimacy. Research Policy, 44(2), 421-437. http://dx.doi.org/10.1016/j.respol.2014.08.003

Ranking Universitário Folha. (2015). Ranking por indicador de inovação. Recuperado de http://ruf.folha.uol.com.br/2015/ranking-de-universidades/ranking-por-inovacao.

Resolução n. 09-COUN. (2003). Regulamenta a proteção de direitos relativos à propriedade industrial e intelectual no âmbito da UFPR. Curitiba, PR: Universidade Federal do Paraná. Recuperado de http://www.prppg.ufpr.br/sites/default/files/documentos/pesquisa/resolucoes/coun0903.pdf

Resolução n. 01 - COUN. (2015). Regulamenta a proteção de direitos relativos à invenção, modelo de utilidade, desenho industrial, programa de computador, topografia de circuito integrado, cultivar e qualquer outro desenvolvimento tecnológico que acarrete o surgimento de novo produto, processo ou aperfeiçoamento incremental, no âmbito da UFPR. Curitiba, PR: Universidade Federal do Paraná. Recuperado de https://drive.google.com/file/d/0By8XpF6NPwpNDRRVUhycGFUNnc/view

Resolução n. 02 - COUN. (2015). Regulamenta o registro e a proteção de direitos relativos à marca, no âmbito da UFPR. Curitiba, PR: Universidade Federal do Paraná. Recuperado de https://drive.google.com/file/d/0By8Xp-F6NPwpYWVoUGRWRW40VEk/view

Rothaermel, F. T., Agung, S. D., \& Jiang, L. (2007). University entrepreneurship: a taxonomy of the literature. Industrial and Corporate Change, 16(4), 691-791. http://dx.doi.org/10.1093/icc/dtm023

Santana, E. E., \& Porto, G. C. (2009). E agora, o que fazer com essa tecnologia? Um estudo multicaso sobre as possibilidades de transferência tecnológica na USP-RP. Revista de Administração Contemporânea, 13(4), 410-429. Recuperado de http://www.scielo.br/pdf/rac/v13n3/v13n3a05.pdf. 65552009000300005

Siegel, D. S., Veugelers, R., \& Wright, M. (2007). Technology transfer offices and commercialization of university intellectual property: performance and policy implications. Oxford Review of Economic Policy, 23(4), 640-660. http://dx.doi.org/10.1093/oxrep/grm036 
Siegel, D. S., Waldman, D., \& Link, A. (2003). Assessing the impact of organizational practices on the relative productivity of university technology transfer offices: an exploratory study. Research Policy, 32(1), 27-48. http://dx.doi.org/10.1016/S0048-7333(01)00196-2

Silva, L. C. S., Kovaleski, J. L., \& Gaia, S. (2013). Gestão do conhecimento organizacional visando à transferência de tecnologia: os desafios enfrentados pelo NIT da Universidade Estadual de Santa Cruz. Produção Online, 13(2), 77-702. http://dx.doi.org/10.14488/1676-1901.v13i2.1314

Vinig, T., \& Lips, D. (2015). Measuring the performance of university technology transfer using meta data approach: the case of Dutch universities. The Journal of Technology Transfer, 40(6), 10341049. http://dx.doi.org/10.1007/s10961-014-9389-0

Wu, Y., Welch, E. W., \& Huang, W. (2015). Commercialization of university inventions: individual and institutional factors affecting licensing of university patents. Technovation, 36(37), 12-25. http://dx.doi.org/10.1016/j.technovation.2014.09.004

Yin, R. K. (2015). Estudo de caso: planejamento e métodos (5a ed.). Porto Alegre: Bookman.

\section{Dados dos Autores}

Rodrigo Assunção Rosa

Rua Itapeva, 432, 01313-902, São Paulo, SP, Brasil. E-mail: rodrigo.assuncao.r@gmail.com

José Roberto Frega

Av. Prof. Lothário Meissner, 632, $2^{\circ}$ andar, Jardim Botânico, 80210-170, Curitiba, PR, Brasil. E-mail: jose.frega@ gmail.com 